\title{
Effects of Site Burning on Multiple Leader Formation and Growth Performance of Selected Acacia Genotypes
}

\author{
Ahmed Mohamed Adam Eldoma1, Sures M. Kumar', Nor Aini Ab Shukor ${ }^{2,3^{*}}$ \\ ${ }^{1}$ College of Forestry and Range Sciences, Sudan University of Science and Technology, Khartoum, Sudan \\ ${ }^{2}$ Department of Forest Management, Faculty of Forestry, Universiti Putra Malaysia, Serdang, Selangor, Malaysia \\ ${ }^{3}$ Institute of Tropical Forestry and Forest Product, Universiti Putra Malaysia, Serdang, Selangor, Malaysia \\ Email: anishukor@yahoo.com
}

Received 28 November 2014; accepted 23 March 2015; published 26 March 2015

Copyright (C) 2015 by authors and Scientific Research Publishing Inc.

This work is licensed under the Creative Commons Attribution International License (CC BY).

http://creativecommons.org/licenses/by/4.0/

(c) (i) Open Access

\begin{abstract}
Loss of apical dominance, resulting in seedlings with more than one leader, generally referred to as multiple leaders (ML), has been a major problem in forest tree plantation in the tropics. A study to examine the effects of site preparation by burning on growth performance and multiple leaders (ML) formation, and its variation in eight-genotypes of Acacia mangium and Acacia auriculiformis was conducted. The design used for this field trial is a randomized complete block design with four replications at two sites (burnt and unburned) and eight genotypes (four from each species), and the effects were monitored for 24 months. There were significant differences at $P<0.05$ between sites and genotypes for the number of ML trees/plot, basal diameter and survival. Differences among the genotypes, in terms of height, were also significant, but not between sites. The site $\times$ genotype interaction was significant only for ML trees per plot. Generally, the number and the size of ML trees per plot in the burnt site were higher and bigger than those in the unburned site. The number of ML trees per plot formed increased exponentially with time, reaching a peak in about four months after their first occurrence and then leveled off to an almost steady state thereafter at both sites. The average number of multiples (leaders) per tree ranged from 2 to 5 at the burnt site whilst at the unburned site, all the ML trees were of two leaders. A. mangium provenances were more responsive to burning than $A$. auriculiformis, whereas at the unburned site, the variation between them was not significant. Based on the above variation, it can be concluded that burning causes ML formation and can affect the growth of these selected Acacia genotypes.
\end{abstract}

\section{Keywords}

Acacias, Genotype, Multiple Leaders, Growth Performance, Site Preparation

\footnotetext{
${ }^{*}$ Corresponding author.
}

How to cite this paper: Eldoma, A.M.A., Kumar, S.M. and Shukor, N.A.A. (2015) Effects of Site Burning on Multiple Leader Formation and Growth Performance of Selected Acacia Genotypes. American Journal of Plant Sciences, 6, 777-784. 


\section{Introduction}

Forest tree plantations in the tropics consist of exotic species mainly of tropical pines and acacias. Even though species trial results provide useful information on performance, adaptability and species-site interaction, extensive research is required to understand the physiology and the genetics of the introduced materials. Recently there has been upsurge of research on acacias throughout the tropics. Acacia mangium and Acacia auriculiformis are two of the fast growing tropical acacias, which have received the highest priority for genetic assessment and improvement other than Acacia aulococarpa and Acacia crassicarpa. Review of Turnbull [1] indicates the extent of Acacia plantations in Asia. In addition, many national and international provenance trials of A. mangium and A. auriculiformis have been reported from different regions and localities such as from China [2], Indonesia [3] [4], Malaysia [5] [6], Thailand [7] [8], Zaire [9] and Vietnam [10] [11]. Reports from Malaysia and Thailand, in particular, indicated that despite their successful introduction and adaptability, both A. mangium and $A$. auriculiformis provenances grown in plantation and trial sites have shown problems in tree form, growth habit and develop multiple leaders (ML) right from the base of the trunk and in some cases heavy epicormic branching with excessive low forking branch.

Multiple leaders (ML) seedlings referred to seedlings with terminal shoots greater in length than $20 \%$ of the dominant or main leader [12]. It is recognized that damage to terminal meristems will generally result in the loss of apical dominance, and severity of ML formation totally depends on the intensity of the damage. Terminal damage to the apical meristem normally can be associated with several biotic and abiotic factors. Studies on fertilization burn, herbicide soil residues, soil toxins and mycoplasmas led to the identification and recognition of some potential causal factors responsible for the repeated and consistency of ML formation in some temperate species [13]-[15]. In some cases, abnormal bud development and root:shoot ratios due to application of herbicide have been identified to increase the terminal shoot damage and eventually lead ML formation. Terminal damage also has been associated with frost and believed to increase the ML incidence in most of the temperate region. However results indicate that it may be reduced by altered nursery cultural practices such as employing early cut-off dates for supplemental nitrogen fertilization and herbicide application [12].

The actual factors that cause the formation of multiple leaders in these species are limited. Although A. mangium shows strong apical dominance, on some sites trees still show a strong tendency to develop multiple leaders from the base. Srivastava [16] related the causes to genetics and site environmental conditions. Others related it to site environmental factors including cultural practices, genetic variations within genotypes and families as well as growth regulators. The standard silvicultural practice to deal with the problem of multiple leader formation is singling, which involves the retaining of one shoot per tree and cutting-off the rest. It is done four to six months after out planting before the formation of heartwood. However, if singling is not done timely, there is always the danger of rot fungus entering through wound and eventually leading to heart rot disease [17] [18].

In forestry practice, the multiple leader development may be denied or favored depending on management objectives and end-use products. Trees, which invariably have a shrub-like growth habit, would not be preferred when clear bole of higher quality is required for sawn timber production. Currently, multiple leader formation is posing a serious problem to $A$. mangium plantation industry in Peninsular Malaysia in terms of wood quality and added cost by the introduction of singling. Branch-related defects can significantly decrease the quality of plantation grown for solid-wood products. Studies on ML were initiated because the occurrence of ML trees in acacia plantation at some trial plots was becoming unacceptably high. Thus, field trial to examine the effects of site preparation by burning on growth performance and multiple leaders (ML) formation and its variation in eight genotypes of $A$. mangium and $A$. auriculiformis was conducted.

\section{Materials and Methods}

Seeds of eight genotypes, four each of $A$. mangium and A. auriculiformis from a seed consignment obtained from the Australian Tree Seed Center, CSIRO Forestry and Forest Products were used. Three of the A. mangium provenances were from Queensland (QLD) and one was from Papua New Guinea (PNG) while two of the $A$. auriculiformis were from Northern Territory (NT) one was from Papua New Guinea (PNG) and one was from Queensland (QLD). The seeds were treated prior germination, following the guidelines provided by CSIRO. They were then transplanted to polyethylene bags $(12 \mathrm{~cm} \times 18 \mathrm{~cm})$, filled with a potting medium of 5:3:2 top 
soil, sand and tropical peat, respectively, two weeks after sowing. Seedlings were then raised in nursery and were given necessary care.

\subsection{Field Outplanting}

The trial was established at the Dunbar Estate of the How Swee Sdn. Bhd. Aur Gading near Kuala Lipis in Pahang, Peninsular Malaysia in August 2010. It is located $4^{\circ} 20.5^{\prime} \mathrm{N}$ latitude and $101^{\circ} 55.5^{\prime} \mathrm{E}$ longitude, at an altitude of $91.5 \mathrm{~m}$ above sea level. The soil of the trial site were described as deep, brownish yellow to yellowish brown fine sandy loam, weak to moderate medium to fine sub angular blocky structure, friable, well drained with sporadic water logging in some part. The terrain was undulating and the parent material was either Shale or Riverine. The soil types are Bungor and Gong Yong series (Malaysian soil classification system). Two sites, burnt and unburned, were selected within the Estate, based on the recent history of land preparation for planting. Site preparation was carried out in some selected compartments, which were either mechanically cleared or mechanically cleaned and followed by broadcast burning of the old rubber trees (Hevea brasilensis). The sturdiest of the seedlings from the nursery production run were selected, conditioned and hardened-off at the nursery. They were then dispatched and transported to the field trial site a week prior to out planting for the purpose of further hardening-off at the planting site. Seedlings of similar size and vigor were selected for the purpose of field establishment. The experimental design used was a randomized complete block (RCBD) with four replications per site. Within each replication, eight genotypes were assigned randomly to eight single line plots of sixteen trees, planted at a spacing of $3 \mathrm{~m} \times 3 \mathrm{~m}$.

\subsection{Data Collection and Analysis}

Six periodic measurements of the ML formation, survival percentage, total tree height and basal diameter were measured for 24 months. Because of the ML formation an adjusted basal diameter was calculated using the geometric mean procedure for all ML trees. The data of the two sites combined and of each individual site were analyzed separately using SAS, version 6.2, for variance to detect the significance of variation of the sources and their interaction.

\section{Results}

\subsection{Multiple Leader Formation}

The result showed significant differences between site preparation methods for survival and basal diameter, ML, $p<0.05$, but not for height. There were also significant differences between genotypes for ML, survival, height and basal diameter, and site $\times$ genotype interaction for ML, $p<0.05$, but not for survival, height and basal diameter (Table 1).

There was also significant difference between the burnt and unburned sites in terms of ML trees/plot. The number of ML trees/plot at the burnt site was higher than the unburned site (Table 2).

Table 1. ANOVA summary on 24-month growth characteristics of A. mangium and A. auriculiformis.

\begin{tabular}{|c|c|c|c|c|c|}
\hline Source of variation & $\mathrm{df}$ & ML & Survival (\%) & Height & Basal diameter \\
\hline Site & 1 & $805.14^{*}$ & $11956.05^{*}$ & $0.04 \mathrm{~ns}$ & $453.10^{*}$ \\
\hline Genotype & 7 & $67.27^{*}$ & $443.47^{*}$ & $3.42^{*}$ & $2848.36^{*}$ \\
\hline Blocks & 3 & $2.02 \mathrm{~ns}$ & $422.72 \mathrm{~ns}$ & $1.61^{*}$ & $524.24^{*}$ \\
\hline Site $\times$ Genotype & 7 & $71.39^{*}$ & $87.81 \mathrm{~ns}$ & 0.38 ns & $113.24 \mathrm{~ns}$ \\
\hline
\end{tabular}

* Significant different at $p<0.05$; ns: not significant different at $p<0.05$.

Table 2. Effect of site preparation methods on mean growth characteristics of A. mangium and A. auriculiformis genotypes.

\begin{tabular}{ccccc}
\hline Site & ML trees/plot (No) & Survival (\%) & Height (m) & Diameter (cm) \\
\hline Burnt & $7.56^{a}$ & $95.11^{a}$ & $5.63^{a}$ & $93.78^{a}$ \\
Unburned & $0.47^{b}$ & $67.77^{b}$ & $5.58^{a}$ & $88.46^{b}$ \\
\hline
\end{tabular}


Means followed by the same letter in a column are not significantly different at $p<0.05$ by Duncan's New Multiple Range Test.

The genotypes showed significant differences in terms of ML tree/plot formation at the burned site. It ranged from 1 (A. auriculiformis, Wenlock River) to 14.75 (A. mangium, Tully Mission Beach). Here, A. mangium showed significant differences between its provenances but $A$. auriculiformis did not. The genotypes also showed significant differences in terms of ML tree/plot formation at the unburned site. It ranged between nil ( $A$. auriculiformis, Elizabeth River) to 1 (A. auriculiformis, May River). At this site A. auriculiformis showed significant differences between its provenances but not for $A$. mangium. The mean ML trees/plots of both sites combined also showed significant difference between the genotypes. It ranged from 0.75 (A. auriculiformis, Wenlock River) to 7.5 (A. mangium, Tully Mission Beach). A. mangium showed significant difference between its provenances. It ranged from 5.5 (SE Daintree) to 7.5 (Tully Mission Beach). But A. auriculiformis did not show any significant difference (Table 3).

Generally, A. mangium produced remarkably higher percentage of ML trees/ plot in the burnt site compared to A. auriculiformis. The value ranged from $66.67 \%$ (SE of Daintree) to 93.66\% (Tully Mission Beach) for A. mangium provenances while it ranged from $6.25 \%$ (Wenlock River) to $20.66 \%$ (Mary River) for A. auriculiformis. However, the variation between the species was not pronounced in the unburned site. It ranged from $1.82 \%$ (Tully Mission Beach) to 5.13\% (SSO Kuranda) for A. mangium while it ranged from nil (Elizabeth River) to 8.88\% (Mary River) for A. auriculiformis (Table 4).

Table 3. Mean of ML trees per plot, height, basal diameter, and survival percentage for the burnt and unburned sites at 24 months.

\begin{tabular}{|c|c|c|c|c|c|c|c|c|c|}
\hline \multirow[b]{2}{*}{ Genotype } & \multirow[b]{2}{*}{ ML (no) } & \multicolumn{2}{|c|}{ Burnt site } & \multicolumn{6}{|c|}{ Unburned site } \\
\hline & & $\mathrm{Ht}(\mathrm{m})$ & $\begin{array}{l}\text { Diameter } \\
(\mathrm{mm})\end{array}$ & $\begin{array}{c}\text { Survival } \\
\text { (\%) }\end{array}$ & $\begin{array}{c}\mathrm{ML} \\
\text { (tree/plot) }\end{array}$ & $\mathrm{Ht}(\mathrm{m})$ & $\begin{array}{l}\text { Diameter } \\
\text { (mm) }\end{array}$ & $\begin{array}{c}\text { Survival } \\
\text { (\%) }\end{array}$ & $\begin{array}{c}\mathrm{ML} \\
\text { (tree/plot) }\end{array}$ \\
\hline \multicolumn{10}{|l|}{ A. mangium } \\
\hline Kuraida, FN-QLD & $13.25^{a b}$ & $6.5^{a}$ & $110.05^{a}$ & $89.06^{a b}$ & $0.50^{\mathrm{ab}}$ & $6.8^{\mathrm{a}}$ & $114.93^{\mathrm{a}}$ & $60.94^{\mathrm{b}}$ & $6.88^{\mathrm{a}}$ \\
\hline Oriomo Province WP & $13.00^{a b}$ & $6.4^{a}$ & $114.88^{a}$ & $93.69^{a b}$ & $0.50^{\mathrm{ab}}$ & $5.1^{\mathrm{ab}}$ & $103.13^{b}$ & $64.06^{\mathrm{ab}}$ & $6.75^{\mathrm{ab}}$ \\
\hline Tully-Mission Beach & $14.75^{a}$ & $6.4^{a}$ & $120.06^{a}$ & $98.44^{a}$ & $0.25^{\mathrm{ab}}$ & $5.7^{\mathrm{b}}$ & $105.12^{\mathrm{b}}$ & $85.94^{\mathrm{a}}$ & $7.50^{\mathrm{a}}$ \\
\hline SE of Daintree & $10.75^{b}$ & $5.83^{a b}$ & $96.97^{b}$ & $84.38^{b}$ & $0.25^{a b}$ & $5.5^{\mathrm{b}}$ & $92.76^{\mathrm{c}}$ & $51.56^{\mathrm{b}}$ & $5.50^{\mathrm{b}}$ \\
\hline \multicolumn{10}{|l|}{ A. auriculiformis } \\
\hline SSO Fiji & $2.00^{c}$ & $5.4^{b}$ & $87.24^{b c}$ & $100.00^{a}$ & $0.75^{a b}$ & $5.6^{b}$ & $85.05^{c}$ & $65.63^{a b}$ & $1.38^{c}$ \\
\hline Elizabeth River & $2.50^{c}$ & $5.2^{b c}$ & $80.34^{c d}$ & $96.88^{a}$ & $0.00^{b}$ & $4.1^{b}$ & $67.45^{\text {ed }}$ & $70.31^{a b}$ & $1.25^{c}$ \\
\hline Wenlock River & $1.00^{c}$ & $4.1^{b e}$ & $70.91^{d}$ & $100.00^{a}$ & $0.50^{a b}$ & $5.3^{b}$ & $75.19^{d}$ & $73.44^{a b}$ & $0.75^{c}$ \\
\hline Mary River & $3.25^{c}$ & $4.4^{c}$ & $69.80^{d}$ & $98.44^{a}$ & $1.00^{a}$ & $4.9^{b}$ & $63.88^{e}$ & $70.31^{a b}$ & $2.13^{c}$ \\
\hline Overall Site Mean & 7.56 & 5.6 & 93.78 & 95.11 & 0.47 & 5.6 & 88.46 & 67.77 & 4.02 \\
\hline $\mathrm{SD}$ & 5.88 & 0.77 & 19.9 & 5.7 & 0.31 & 0.54 & 18.71 & 10.02 & 1.29 \\
\hline
\end{tabular}

Means followed by the same letter in a column are not significantly different at $p<0.05$ by Duncan' New Multiple Range Test.

Table 4. Comparison of ML\% occurrence between the burnt and unburned sites by genotype.

\begin{tabular}{|c|c|c|c|c|}
\hline \multirow{2}{*}{ Genotype } & \multicolumn{2}{|c|}{ ML (trees/plot) } & \multicolumn{2}{|c|}{ ML (\%) } \\
\hline & Burnt & Unburned & Burnt & Unburned \\
\hline A. mangium Tully Mission Beach & 12 & 0.5 & 93.66 & 1.82 \\
\hline A. mangium SSO Kuranda & 9.5 & 0.75 & 92.98 & 5.13 \\
\hline A. mangium Oriomo Province WP & 11.25 & 0.75 & 83.87 & 4.88 \\
\hline A. mangium SE Daintree & 9.5 & 0.25 & 66.67 & 4 \\
\hline A. auriculiformis Mary River & 3.25 & 1.25 & 20.63 & 8.88 \\
\hline A. auriculiformis Elizabeth River & 4.5 & 0.25 & 16.13 & 0 \\
\hline A. auriculiformis SSO Fiji & 3.5 & 0.75 & 12.5 & 7.14 \\
\hline A. auriculiformis Wenlock River & 1.5 & 0.5 & 6.25 & 4.26 \\
\hline
\end{tabular}




\subsection{Temporal Development of ML Trees}

It took about 7 to 8 months for the planted trees to fully develop and obviously display the ML growth habit. Table 5 illustrates the trend of ML development for A. mangium and A. auriculiformis genotypes through time and also compares the variation between the individual genotypes at the burnt and unburned sites. Generally the number of ML trees/plot formed increased exponentially with time, reached a peak in about four months after their first occurrence and then leveled off to an almost steady state thereafter at both sites (Figure 1). The average number of multiples trunks per tree ranged from 2 to 5 at the burnt site whilst at the unburned site all the ML trees was of the two-stem category. At the burnt site $78.30 \%$ of the total number of ML trees was of the two-stem category, $19.15 \%$ of the three-stem category, $2.13 \%$ of the four-stem category and only $0.43 \%$ was of the five-stem category. Figure 2 shows the number of ML trees by genotypes in each of the four-number category (2 ML to $5 \mathrm{ML}$ ). A. auriculiformis SSO Fiji (PNG) and Wenlock River (QLD) had all their multiples in the two-stem category while the remainder had mixed proportion of the stem categories.

\section{Discussion}

Trees that develop multiple leader growth habit ultimately lose their timber value. The intensive investigation reports made by Hofstra et al. [19], Holopainen [20] and Birk [21] regarding multiple leader formation on temperate forest trees, both at the nursery and field level, indicate that multiple leader's growth habits are threats to

Table 5. Temporal development of growth characteristic of A. mangium and A. auriculiformis genotypes by site preparation method.

\begin{tabular}{ccccccccc}
\hline \multirow{2}{*}{$\begin{array}{c}\text { Age } \\
\text { (month) }\end{array}$} & \multicolumn{2}{c}{ Height $(\mathrm{m})$} & \multicolumn{2}{c}{ Diameter $(\mathrm{mm})$} & \multicolumn{2}{c}{ ML (tree/plot) } & \multicolumn{2}{c}{ Survival (\%) } \\
\cline { 2 - 9 } & Burnt & Unburned & Burnt & Unburned & Burnt & Unburned & Burnt & Unburned \\
\hline 4 & $0.927 \pm 0.20$ & $0.976 \pm 0.23$ & $10.462 \pm 1.58$ & $8.725 \pm 1.76$ & $0.00 \pm 0.00$ & $0.00 \pm 0.00$ & $96.68 \pm 6.35$ & $83.38 \pm 14.7$ \\
7 & $1.573 \pm 0.29$ & $1.555 \pm 0.37$ & $22.108 \pm 4.14$ & $15.597 \pm 3.56$ & $0.00 \pm 0.00$ & $0.00 \pm 0.00$ & $96.48 \pm 6.34$ & $76.75 \pm 17.1$ \\
9 & $2.276 \pm 0.35$ & $2.181 \pm 0.40$ & $36.54 \pm 11.98$ & $25.124 \pm 6.56$ & $5.187 \pm 3.45$ & $0.43 \pm 0.67$ & $96.26 \pm 6.53$ & $75.77 \pm 17.8$ \\
13 & $3.594 \pm 0.50$ & $3.168 \pm 0.54$ & $52.476 \pm 11.70$ & $39.196 \pm 9.70$ & $6.438 \pm 4.38$ & $0.531 \pm 0.72$ & $96.09 \pm 6.69$ & $72.85 \pm 17.8$ \\
16 & $4.583 \pm 0.70$ & $3.964 \pm 0.62$ & $67.499 \pm 14.50$ & $56.499 \pm 13.58$ & $6.531 \pm 4.31$ & $0.625 \pm 0.79$ & $95.89 \pm 6.66$ & $68.53 \pm 19.3$ \\
23 & $5.632 \pm 0.89$ & $5.582 \pm 0.96$ & $93.78 \pm 20.52$ & $88.459 \pm 19.66$ & $6.781 \pm 4.54$ & $0.625 \pm 0.79$ & $95.10 \pm 8.06$ & $67.77 \pm 18.5$ \\
\hline
\end{tabular}

Note: Mean \pm Standard Deviation.
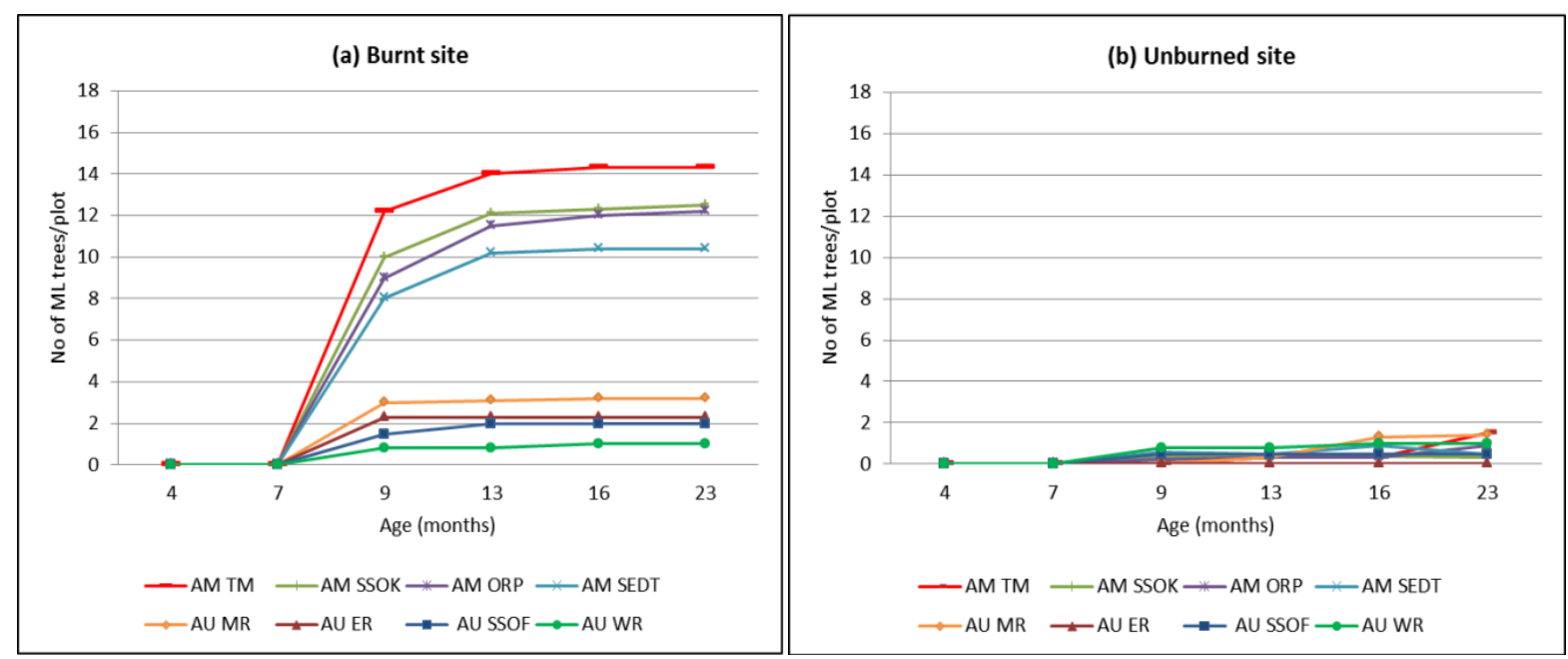

Figure 1. The trend and variation of ML development with time of A. mangium and A. auriculiformis genotypes at (a) burnt and (b) unburned sites. Key: abbreviations of the genotypes; AM TM = A. mangium Tully Mission Beach; AM SSOK = A. mangium SSO Kuranda; AM ORP = A. mangium Oriomo Province WP; AM SEDT = A. mangium SE Daintree; AU MR = A. auriculiformis Mary River; AU ER = A. auriculiformis Elizabeth River; AU SSOF = A. auriculiformis SSO Fiji; AU WR = A. auriculiformis Wenlock River. 


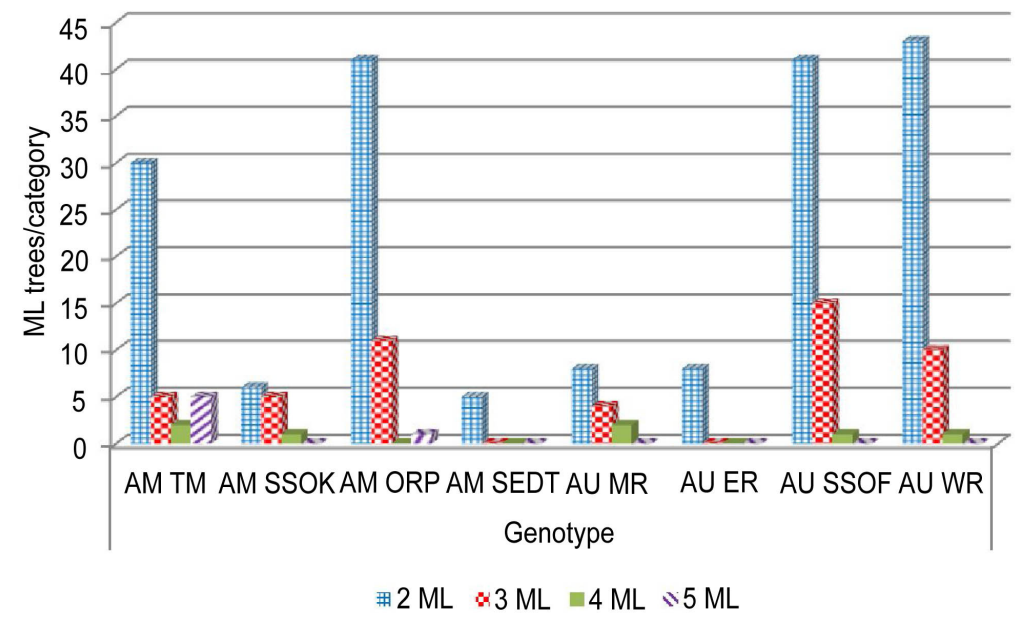

Figure 2. The proportion of ML trees in the four stem-categories by genotype. Note: abbreviations are the same as in Figure 1.

timber trees development. The result of the present study in agreement with the suggestion that environment has much influence on form and growth habit. In this context, about half $(49.09 \%)$ of total number of planted trees at burnt site had multiple trunks as compared to only $4.25 \%$ at the unburned site. The result of the present study also revealed that the problem of ML growth habit in relation to site preparation method might be a potential problem for A. mangium, in particular. All four A. mangium provenances at the burnt site had significantly higher number of ML trees per plot compared to all four A. auriculiformis provenances (Table 3) while at the unburned site this was not the case. The genotypes varied a great deal in their response to site preparation by burning. At the burnt site $85 \%$ of the total number of the ML trees was from the provenances of A. mangium while only $15 \%$ were from A. auriculiformis. At the unburned site, however, A. auriculiformis contributed $60 \%$ of the total ML trees and A. mangium 40\%. Taking into consideration the highly significant difference between the burnt and unburned sites, A. mangium provenances were more responsive to burning than A. auriculiformis, as land preparation method. However, this conclusion is not in full agreement with the findings by Khasa et al. [9] from a trial in Zaire, where A. auriculiformis had multiple stem of an average of three stems per tree while $A$. mangium had only single stem at four sites, in which site prepared by burning of the vegetation after mechanical clearing. However, the details of the provenance used were not reported. This was reflected by the fact that $A$. auriculiformis genotypes had no considerable variation in ML/plot across the two sites while A. mangium genotypes had highly significant differences in ML/per plot across the two treatments. The effect of ML leaders to the quality of timber should also not to be overlooked. If the aim of a plantation is to produce quality timber trees, then ML trees need to be rejected on the ground of ML formation. Otherwise, additional cost for silvicul-tural practices such as singling would be compulsory. Singling, on the other hand, if not done on time, will also has its own disadvantages as trees that have developed heartwood, if singled will be affected by rot fungus [17] [18]. However, ML formation are accepted or even desirable if the objective of the plantation is to produce fuel wood, poles, and pulp and paper production.

Regarding the survival rate, the result of the trial indicated that all the genotypes survived well at the burned site with a site mean of $95.11 \%$, ranging between $84 \%-100 \%$, while the survival at the unburned site was comparatively low, with an overall site mean of $66.67 \%$, ranging from $54.56 \%$ to $73.44 \%$. However the mean of both sites combined ranged from $67.90 \%$ to $92.13 \%$. A. mangium from the SE of Daintree showed the lowest survival rate. Generally, the results of the survival rate obtained in this study were comparable with the trends experienced in many of the A. mangium and A. auriculiformis provenances trials in the humid tropics [5] [6] [22]-[25]. The reasons for the low survival rate at the unburned site may be attributed to weed competition, animal trampling and shade.

The result of the 24 months observation, however, showed that there was no significant difference in terms of height between the provenances of each of the two Acacia species but only between the genotypes (Table 1). These results were in accordance with the reports of Peterson and Havmoller [26] for A. mangium, at the age of six months, in Philippines, but not with the result obtained by Atipanumpai [22] for A. mangium, at the age of 30 
months, in Thailand where the species differed significantly in height. Sim and Gan [27] also found substantial differences in height between Acacia species but less between A. mangium and A. auriculiformis provenances. In general, A. mangium out performed A. auriculiformis provenances in terms of height growth. Basal diameter growth also showed significant differences in both sites, among genotypes at each site and at both sites combined. The trends of diameter growth were reported by Kamis et al. [5]; Nor Aini et al. [6]; Khasa et al. [9]; Atipanumpai [22] and Gwaze [24].

\section{Conclusion}

The results of the study are in agreement with the suggestion that environment has much influence on form and growth habit of Acacia genotypes. The use of fire to clear land for A. mangium and A. auriculiformis genotypes induces ML formation. It was also observed that $A$. mangium provenances were more responsive to ML formation than A. auriculiformis provenances. The number ML/tree ranged from two to five at the burnt site compared with only two at the unburned site for both species. The problem of ML growth habit of Acacia provenances in relation to site preparation method might be a potential problem for establishment of commercial plantation area, if the high quality grade timber was the target of a plantation. If fuel wood or small construction poles or even pulp and paper production is the objective, then the ML formation would be accepted and not greatly affect the end product, and in fact, it may be desirable in some cases. However, this could be utilized for better planning, and management of plantation area with option of other suitable methods depends on the objective of the end product, site condition and environment factors.

\section{Acknowledgements}

This work was funded mainly by Intensification of Research in Priority Area (IRPA) grant provided by Ministry of Science, Technology and the Innovative (MOSTI). This work is also partly supported by the scholarship grant from the Acacia project of Trop Bio Research, Universiti Putra Malaysia. We are indepted to Mr Khongsak Pinyopusarerk of CSIRO Forestry and Forest Products, Australia for providing seeds lots and Mr How Swee the owner of Dunbar Estate, Aur Gading, Kuala Lipis for the establishmant of the field trial. Authors also thank all colleagues for providing support and facilities and those who contributed directly or indirectly to improve this manuscript.

\section{References}

[1] Turnbull, J.W., Midgley, S.J. and Cossalter, C. (1998) Tropical Acacias Planted in Asia: An Overview. In: Turnbull, J.W., Crompton, H.R. and Pinyopusarerk, K., Eds., Recent Development in Acacia Planting, Proceedings of an International Workshop, Vietnam (ACIAR, Canberra), 27-30 October 1997, 383 p.

[2] Chung, T.Y., Hsu, Y.R., Chang, T.Y. and Yang, J.C. (1990) Provenance Variation of Tree Height, Diameter at Breast Height and Volume in Acacia mangium at Young Ages. Quarterly Journal of Chinese Forestry, 23, 77-86.

[3] Nurhasybi, Sudrajat, D.J. and Diatna, K. (2009) Identification of Acacia mangium Provenances for Solid-Wood Forest Plantations. Journal of Forestry Research, 6, 1-16.

[4] Vuokko, R., Adjers, G. and Temmes, M. (1992) Afforestation of Imperata cylindrica Grasslands Using Acacia Species. In: Kamis, A. and Taylor, D.A., Eds., Tropical Acacias in East Asia and the Pasific, Proceedings of the $1^{\text {st }}$ Meeting of the Consultative Group for Research and Development of Acacias, Phuket, 1-3 June 1992, 106 p.

[5] Awang, K., Venkateswarlu, P., Shukor, N.A.A., Adjers, G., Bhumibhamon, S., Kietvuttinone, B., Pan, F., Pitpreechae, K. and Simsirie, K. (1994) Three Year Performance of International Provenance Trials of Acacia auriculiformis. Forest Ecology and Management, 70, 147-158. http://dx.doi.org/10.1016/0378-1127(94)90082-5

[6] Nor Aini, A.S., Awang, K., Venkateswarlu, P. and Senin, A.L. (1994) Three-Year-Performance of Acacia auriculiformisat Serdang, Malaysia. Journal of Tropical Agricultural Sciences, 17, 95-102.

[7] Luangviriyasaeng, V. and Pinyopusarerk, K. (2002) Genetic Variation in Second-Generation Progeny Trial of Acacia auriculiformis in Thailand. Journal of Tropical Forestry Science, 14, 131-144.

[8] Pinyopusarerk, K., Luangviriyasaeng, V., Pransilpa, S. and Meekeo, P. (1998) Performance of Acacia auriculiformis in Second-Generation Progeny Trial in Thailand. In: Turnbill, J.W., Crompton, H.R. and Pinyopusarerk, K., Eds., Recent Developments in Acacia Planting, Proceedings of an International Workshop, Vietnam (ACIAR, Canberra), 27-30 October 1997, $383 \mathrm{p}$.

[9] Khasa, P.D., Vallee, G., Magnussen, C.C. and Bousquet, J. (1995) Performance of Five Tropical Tree Species on Four 
Sites in Zaire. Commonwealth Forestry Review, 74, 129-137.

[10] Phi, H.H. (2009) Genetic Improvement of Plantation Grown Acacia auriculiformis for Sawn Timber Production. Ph.D. Thesis, Swedish University of Agricultural Sciences, Sweden.

[11] Huynh, D.N. and Nguyen, Q.D. (1998) Acacia Species and Provenance Trials in Central Northern Vietnam. In: Turnbull, J.W., Crompton, H.R. and Pinyopusarerk, K., Eds., Recent Developments in Acacia Planting, ACIAR, Canberra.

[12] Webb, D.P. and Reese, K.H. (1984) Multiple Leadering of Coniferous Nursery Stock. Ontario Joint Report No. 3, Canadian Forestry Service, Great Lakes Forest Research Centre, Sault Ste. Marie, 8 p.

[13] Thomas, J.B. (1958) The Production of Lammas Shoots on Jack Pine in Ontario. Forestry Chronicle, 34, 307-309. http://dx.doi.org/10.5558/tfc34307-3

[14] Rudolph, T.D. (1964) Lammas Growth and Prolepsis in Jack Pine in the Lake States. Forest Science-Monograph, 70 p.

[15] Gross, H.L. (1983) Injuries to Terminal Shoots Cause Multiple-Leadered Nursery Seedlings. Ontario Information Report O-X-347, Canadian Forestry Service, Great Lakes Forest Research Centre, Sault Ste. Marie, 12 p.

[16] Srivastava, P.B.L. (1993) Silviculture Practices. In: Awang K. and David, A.T., Eds., Acacia mangium Growing and Utilization, MPTS Monograph Series No. 3, Winrock International and FAO, Bangkok.

[17] Mead, D.Y. and Speechly, H.T. (1989) Growing Acacia mangium for High Quality Sawlogs in Peninsular Malaysia. Proceedings of the Regional Symposium on Recent Developments in Tree Plantations of Humid/Sub-Humid Tropics of Asia, Serdang, 5-9 June 1989.

[18] Tang, H.C. and Zulkifli, M. (1992) Management Practices of Acacia mangium Plantation in Peninsular Malaysia. Proceedings of the International Symposium on Harvesting and Silviculture for Sustainable Forestry in the Tropics, Kuala Lumpur, 5-9 October 1992.

[19] Hofstra, G., McLeod, C.L. and Ensing, J. (1988) The Incidence and Performance of Multiple Leadered Seedlings of Black and White Spruce in Canadian Nurseries. North Journal of Applied Forestry, 5, 99-103.

[20] Holopainen, J.K. (1990) The Relation between Multiple Leaders and Mechanical and Frost Damage to the Apical Meristem of Scot's Pine Seedlings. Canadian Journal of Research, 20, 280-284. http://dx.doi.org/10.1139/x90-041

[21] Birk, E.M. (1991) Stem and Branch Form of 20 Year-Old Radiata Pine in Relation to Previous Land Use. Australian Forestry, 54, 30-39. http://dx.doi.org/10.1080/00049158.1991.10674554

[22] Atipanumpai, L. (1989) Acacia mangium: Studies on the Genetic Variation in Ecological and Physiological Characteristics of Fast-Growing Plantation Tree Species. Acta Forestalia Fennica, 206, 1-99.

[23] Luangviriasaeng, V., Pinyopusarerk, K. and Williams, E.R. (1991) Results at 12 Months of A. auriculiformis Trials in Thailand. In: Turnbull, J.W., Ed., Advances in Tropical Acacias Research, ACIAR Proceedings No. 35, Bangkok.

[24] Yuang, M. and Yutian, Z. (1991) Results from a Four-Year-Old Tropical Acacia Species/Provenance Trial on Hainan Island, China. In: Turnbull, J.W., Ed., Advances in Tropical Acacias Research, ACIAR Proceedings No. 35, Bangkok.

[25] Gwaze, D.P.J. (1992) Provenance Trials of Acacia holosericea and Acacia auriculiformis. Journal of Tropical Forestry Science, 6, 65-73.

[26] Petterson, H. and Harmoller, P. (1984) Provenance Test and Breeding Strategies for Acacia mangium and Eucalyptus Species in Philippines and India. In: Barnes, R.D. and Gibson, G.L., Eds., Provenance and Genetic Improvement Strategies in Tropical Forest Trees, CFI and Zimbabwe Forestry Commission, Zimbabwe, 219-234.

[27] Sim, B.L. and Gan, E. (1991) Performance of Acacia Species on Four Sites in Sabah Forest Industries. In: Turnbull, J.W., Ed., Advances in Tropical Acacias Research, ACIAR Proceedings No. 35, Bangkok. 